TURIZAM

Volume 16 , Issue 4

180-192 (2012)

\title{
Behavior of Serbian Tourists During Economic Crisis: Two Empirical Researches ${ }^{1}$
}

\author{
Marija Najdić*, Nataša Sekulović* \\ Received: November 2012 | Accepted: December 2012
}

\begin{abstract}
Tourist's behavior research is focused on understanding and explaining the factors that affect tourist's preferences and holiday destination choice. In this paper is analyzed the impact of the global economic crisis on the preferences toward leisure travels of the residents from Serbia. The paper is based on researches conducted in 2006-2009, through travel agencies and in 2011 on the general population major of age with support of TNS Medium Gallupa. Better understanding of the perception process and how tourists react to certain factor can give more accurate information on the dynamics of tourism demand and its dependence on tourist's perception.
\end{abstract}

Key words: Tourist behavior, global economic crisis, holiday destination, perception, preferences

\section{Introduction}

Tourism is highly crisis sensitive, both to those caused by economic factors as well as to those caused by non-economic factors (terrorism, epidemics, natural catastrophes, etc.). During the last two decades, international tourism has been exposed to negative factors, inter alia: oil crises, Gulf war, terror attacks in US, SARS, bird flue, Asian economic crises, tsunami in 2005 and 2OII, war in Iraq, etc. Despite all of those, in its development since the '5OS tourism had a positive growth tendency with occasional periods of stagnation and recession caused by the adverse effect of negative factors which have not impeded the long term positive tendency. This is also a proof of high resilience and capacity of recovery of tourism. The development of tourism directly corresponds with the global economic development, and in accordance to that, until the first half of 2008 , it has been registered a significant growth rate of international arrivals of 6\% (UNWTO prognosis on yearly basis is 4\% until 202O). However, in the second half of 2008 a sharp decrease of growth rates in international tourism was registered, ending 2008 with a growth of international arrivals of $2 \%$ for the entire

\footnotetext{
Parts of researches have been presented at 8th Circle International Conference for Marketing, Management, Finance, Consumer Behavior, Tourism and Retailing Research, Dubrovnik, Croatia, 2011 and published in: International Journal of Management Cases, 13 (3): 18-23 and in the Singidunum Review, 8(2): 111-118

* Faculty of Tourism and Hospitality Management, Singidunum University, Danijelova 32, Belgrade, Serbia, Corresponding author: mnajdic@singidunum.ac.rs
} 
year. Particularly warring was the fact that the crisis primarily affected the most developed countries in the world that are also the main tourism demand generators (Unković, Sekulović, 20IO). Considerng that the research in 2OII and partially in 2008-2009 have been conducted during the Global economic crises, its effect has been in the focus when the preferences of tourists towards leisure tourism are analysed.

According to Aaker et al. (2OO8) study of tourist behavior and their preferences need to be conducted in intervals so that they can be monitored over a longer period. In this paper, the changes are evidenced in tourist movements regarding to the three destinations (Montenegro, Croatia, Bulgaria) in 2006, 2009. and 2OII, analyzed by statistical and two empirical research. The importance of discovering the expectations and preferences of tourists is in facilitating the implementation of external benchmarking of holiday destinations. Refer to Bakić carrying out market and competition analysis will give the answers on the basic questions for every destination: who are our tourists, how many there are in the market, what are their socio-economic and psychographic characteristics, where they come from and which means of transport they use? (Bakić, 2005). We come to the main aims of tourists behavior research:

- To predict the behavior of tourists on the basis of available information

- To understand and explain this behavior in order to improve theoretical knowledge in this area

Kozak and Rimmington (I999) suggested that evaluation should be conducted with the collection, systematization and analysis of tourist surveys that examine perception, preferences and the past experiences of tourists in relation to multiple-choice between several holiday destinations. We have used data's from 2006, 2009 and 20II. monitoring changes that occurred regarding tourist perception of holiday destination in different economy clime and presented how different factors influenced on choice of a holiday destination.

\section{Tourist Behaviour and Economic Crisis}

The dominant paradigm, in explaining and predicting tourist behavior, is based on processing information's. Using the scientific method in research through techniques such as surveys, observation and experiment, it focuses on explaining how people receive, process and use information. In this case, (Miljević, 2006) indicates that the most likely effects of communication on tourists, including mass communication, are going to reinforce their existing opinions, attitudes and behavioral tendencies.

It is common known that, before the cognitive process, the individual feels emotions. The interpretation is actually a process in which the emotional factors and the specific information give meaning and purpose on any cognitive or affective (emotional) level. This clearly indicates that this is a subjective assessment which may be different for each individual, and therefore is a key element of tourist research in the strategy development of the tourist destinations and its competitiveness in the market.

It has been evidenced that, during crises, tourists behave differently when holiday travels are concerned. Tourists reluctantly give up of travel, but they change their preferences which reflect as shorter travels, travels to closer destination in order to reduce transportation costs, more affordable, cheaper, accommodation, reduction of consumption, etc. 


\section{Literature Review}

Throughout history, understanding the psychology of consumers is becoming more advanced. The basis was given by Mayo and Jarvis (I98I) when they presented in their papers from psychology of travel cognitive and affective drivers and their social impact on decision making process. They included the perception, learning, personality, motivation and attitudes as factors affecting the consumers behavior, pointing out that by focusing on the consumer rather than the statistical average, and understanding the psychology of tourists, rather than demographic characteristics, can be achieved new insights into consumer behavior in tourism. Plutchik defined a year earlier the scale of emotions that gives insight into the changes in emotional state of the respondents and opposed by the scale of Mehrabian and Russell's, contains questions about expectations which were considered to have a major impact on the tourists perception of tourist services. Further studies have continued Johnson and Thomas (I992) introducing in literature the role of typology of tourists, symbolic consumption, market segmentation, image destination and satisfaction. Uysal deals in his works in (1994) consumer expectations, behavior of individual tourists and those who use holiday packages, issues of cultural diversity, motivation to travel, consumer behavior, etc. Parasuraman (1994) researches the quality of services as a result of the difference between expectations-preformance (SERVEQUAL method). Cronin and Taylor presented in their work (I992) other methods (SERVPERF) for the evaluation of service delivery. Ross (I998) analysis individual tourists focusing on attitudes, motivation, personality, environmental factors and organizational structure in contributing to destination image, tourist industry as well as on the factors of employment and the social impact that tourism has on the destination.

On the other hand, many authors have analysed the effect of the crisis on tourism, and its effects on tourism demand. Since not all crises have the same impact on tourists, we shall present a short review of crises that affect tourism, and in particular we shall focus on economic crises.

According to Glaesser there are several types of negative invents that have subsequently caused tourism crises. In the Table I is presented the classification of crises upon their causes with some examples (Glaesser, 2004):

Henderson defines certain factors that can be classified within certain domaines: economy, politics, socio-cultural, environmental, technological and commercial; in that sense he distinguishes internal and external crises threats.

The clear identification of the causes of the crises shall help in the determination of its consequences and relevance, and its classification form major to minor crisis, measured on the basis of the number of people is affecting and the costs it has caused (Henderson, 2007, 5).

This reflects to both international and national tourism, and upon the type, nature and intensity of those factors, depends the relevance of their impact on the national and/or international

tourism. E.g., the growth of the price of hotel services at a certain destination can influence negatively the national tourism demand if it is not followed by a growth of personal income, while it might not effect the international arrivals to that country, particularly not if the originating countries have experienced a growth of personal income or currency fluctuations are positive. Simultaneously, in this case, domestic population might change for other destination which might effect negatively on the tourism balance. Economic conditions, in the main demand generating countries, as well as in the main reception countries, define the trends of tourism and the patterns of tourism consumptions. The change of the nature of economic factors depends if those factors shall stimulate positively or impact negatively the tourism demand (Henderson, 2007). 
Table 1. Classification of crises

\begin{tabular}{|l|l|}
\hline Causes & Environmental \\
\hline Wars, unrest & Tanker Erica Catastrophy 1999 \\
\hline Coup d'etat in Gambia, 1994 & Earthquake in Umbria, Italy, 1997 \\
\hline Coup d'etat in Fiji, 1987 and 2000 & Algae florishing in Rimini, Italy, 1989 and 1990 \\
\hline Unrest in Los Angeles and San Francisko 1992 & Hurricane Mitch, 1998 \\
\hline & Eruption of Mt. Etna, Italy, 2001 \\
\hline Deseases and Epydemics & Terrorism, Crime \\
\hline Legionnaire's Desease in Spain, 2001 & Cynide Attacks in Japan, 1995 \\
\hline Mad Cow Desease, 1993 & ETA Terror Campaign, Spain, during '80s \\
\hline Mouth and Foot Desease, 2001 & Attacks on Tourists in Florida, USA, 1993-1994 \\
\hline Antrax, 2001 & Hostage Crisis, Filippines, 2000 \\
\hline & Terror Attacks in Turkey, '90s \\
\hline Transport & Political, economic \\
\hline Ferry Estonia, 1994 & EU Boycott of Austria, 2000 \\
\hline Concorde Airplane Crash, 2000 & Asian Financial Crises, 1997 \\
\hline Train Accident in Eschede, 1998 & \\
\hline
\end{tabular}

Table 2. Internal and external crises threats by domaines

\begin{tabular}{|c|c|c|}
\hline Domain & External & Internal \\
\hline \multirow{3}{*}{ Economic } & Recession & Rising costs \\
\hline & Currency fluctuations & Falling revenues \\
\hline & Taxation & Unprofitability \\
\hline \multirow{4}{*}{ Political } & Government policy & \\
\hline & International relations & \\
\hline & Instability & \\
\hline & Terrorism & \\
\hline \multirow{2}{*}{ Socio-cultural } & Unrest & Staffing \\
\hline & Crime & Cultural conflicts \\
\hline \multirow{4}{*}{ Environmental } & Natural phenomena & Overdevelopment \\
\hline & Natural disasters & Environmental degradation \\
\hline & Pollution & \\
\hline & Health scares & \\
\hline \multirow{4}{*}{ Technological } & Computer systems failure & Transport accidents \\
\hline & Mechanical failure & \\
\hline & Design faults & \\
\hline & Fire & \\
\hline \multirow{4}{*}{ Commercial } & Regulations & Competition \\
\hline & Government intervention & Labor disputes \\
\hline & & Management decisions \\
\hline & & Human error \\
\hline
\end{tabular}




\section{Research Methodology}

Starting from Aaker, et al. (2008) assumption that the attitudes lead to behavior and that is easier to ask questions about opinions, then to observe and interpret the actual behavior, we used survey and scaling as data collection techniques.

The first research was conducted in the period 2006-2009 had a sample of 740 interviewed tourists from Serbia (Najdić, 2OII). The questionnaires were given to participants during their trip to holiday destination. The construction of the questionnaire consisted of four parts: The first part related to demographic characteristics of respondents (place of package holiday payment, age, average income). The second part of the questionnaire contained questions that reflect the image of destinations, and define the tourist brand experience of chosen destination. The third part of the questionnaire comprised the type of open ended questions so the respondents get more involved in researching and to investigate the intention of the respondents and their expectations regarding future destination choice. One of the main steps in evaluation and development of a destination brand is to determine the tourists perception regarding to specific destinations (Popesku, 2008). For this evaluation in survey was used a Porters method (1980) of evaluating competitive advantages ${ }^{2}$ such as: market share ${ }^{3}$ and industry competitors ${ }^{4}$. For market assessments we used direct comparison of several competitive European destinations (Montenegro, Croatia, Bulgaria). The last, fourth part was related to the organization of trip and duration of holiday. Since this sample has included the segment of the tourists who use travel agencies, i.e. holiday packages, in this analysis are also implemented the results of the second research conducted in 2OII, on a stratified sample of IOO5 interviewed citizens major of age (Sekulović, 2OII, with the field work of TNS Media Gallup). Territory of Serbia was divided in four stratums: Belgrade, Vojvodina, Western Serbia, Eastern Serbia and each one was represented proportionally to the total number of population major of age. The questionnaire consisted of questions related to demographic characteristics of respondents, travel habits (including travel frequency) and preferences regarding destination, transport, lodging, etc., as well as specific questions related to the impact of the economic crisis on traveling and questions related to the other factors which could have impact on the respondents in the same period.

Combination of these two researches gives a better insight in the matter of tourist's preferences, as well as in the factors that influence on tourists perception regarding to choice of a holiday destination, including the impact of Global economic crises on tourist movements.

\section{The Results of Surveys}

The results of the research conducted in 2OII, which included the entire population of Serbia major of age, indicate that the percentage of the population that went for a leisure travel in the period 2006-2009, was 3I\%, and, on average, once per year. Out of this number 47,4\% had their holidays out of Serbia, significantly less, 37,6\%, in Serbia, and I5\% both in Serbia

2 Michael Porter developed a theory of company value chains (I980) using competitive positioning framework called 5 forces (The Diamond of Competitive Advantage). The five forces are competitive factors which determine industry competition and include: suppliers, rivalry within an industry, substitute products, customers or buyers, and new entrants

3 Market share is calculated as a percentage of total sales in the observed activity in a given time

4 Industry competitors in a tourism industry refer to holiday destination with similar tourist product 


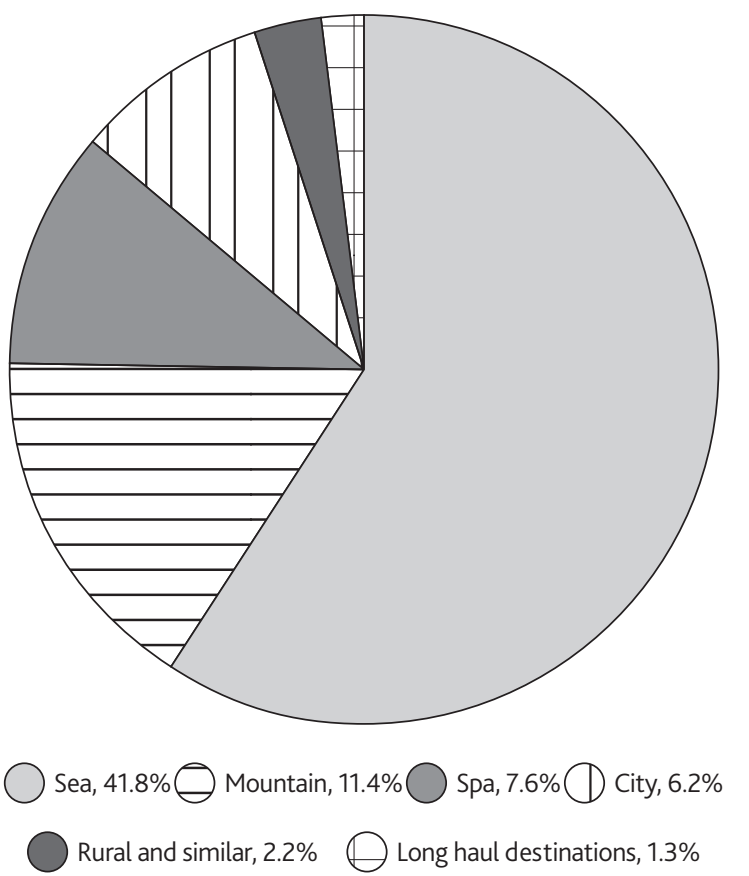

Figure 1. Leisure travel destination preferences of the population of Serbia (\%), in 2011.

and abroad. This result doesn't come as a surprise, if we consider that as destination the sea is overwhelmingly predominant in comparison to other destinations (mountains, spas, cities, and other), as shown in Figure I.

The global economic crisis has reduced the number of tourists who travelled for holidays by $3 \%$ in 2010 in respect to 2009 reaching a level lower than in 2005 . This was the first decrease after 5 years growth since 2003-20045 (Unković, Zečević, 2OII). More than 43\% of the tourists have answered that they have decreased the number of leisure travel in comparison to the period before 2008. Furthermore, the decrease is followed also in the domestic tourist turnover in 2010 that has fallen by $4 \%$ in respect to 2009.

Table 3. Have you reduced in 2009 and in 2010 the number of leisure travels?

\begin{tabular}{|l|r|}
\hline & $\%$ \\
\hline Yes, significantly & 30,6 \\
\hline Yes, little & 12,4 \\
\hline No & 33,9 \\
\hline NA & 23,0 \\
\hline Total & 100,0 \\
\hline
\end{tabular}

As the main reason for the decrease of leisure travel, I5,7\%, of the tourists who have reduced the number of leisure travel, have indicated directly as main factor the effect of the global economic crisis, and an additional $26,2 \%$ has indicated a decrease of income due to the

5 In 2003 has been registered a decrease of tourism on global level mainly due to non economic factors 
crisis, which means that $4 \mathrm{I}, 9 \%$ of the tourists have indicated financial reasons as the main reason why they have reduced their leisure travel. This figure reflects essentially the number of the tourists that have decreased their leisure travel, $43 \%$.

Non economic factors such as viruses and diseases as AIHI pandemic (that afflicted the World in 2009 and 2OIO) or safety/security concerns have impacted I,I\%, i.e. O,5\% of the tourists, and additional $6,8 \%$ indicates other reasons.

In addition, the economic crisis has affected also the accommodation preferences, and on a lesser extent, also transport methods preferences.

Table 4. Has the crisis influenced your choice of accommodation?

\begin{tabular}{|l|r|}
\hline & $\%$ \\
\hline Yes & 47,8 \\
\hline No & 38,2 \\
\hline Do not know/no answer & 14,1 \\
\hline Total & 100,0 \\
\hline
\end{tabular}

Table 5. Has the crisis influenced your choice of the transport method?

\begin{tabular}{|l|r|}
\hline & $\%$ \\
\hline Yes & 38,3 \\
\hline No & 48,4 \\
\hline Do not know/no answer & 13,3 \\
\hline Total & 100,0 \\
\hline
\end{tabular}

Obviously we have to consider that the most represented method of transport of the tourists is bus or personal vehicle, and that this has also contributed to smaller changes in the method of transport preferences.

As far as other non economic factors are concerned it is interesting to note that the effects of the EU visa liberalization in 2009 have had a limited impact on the decision of the tourists where to travel for leisure as it is shown in table 6 .

Table 6. Has the EU visa liberalisation had an effect on your decision where to travel?

\begin{tabular}{|l|r|}
\hline & $\%$ \\
\hline Yes & 17,9 \\
\hline No & 69,7 \\
\hline Do not know, no answer & 12,3 \\
\hline Total & 100,0 \\
\hline
\end{tabular}

On the basis of these answers we can conclude that the effects of the EU visa liberalization for the tourists of Serbia were mainly on the minority of tourists, those who usually travel every year (Sekulović, 2OII). 


\section{The perception of Serbian tourists towards Montenegro, Croatia and Bulgaria as a holiday destination}

The main goal of qualitative determination of a holiday destination perception is to achieve a positive brand status but also to identify negative factors affecting the attractiveness of other destinations in the region. As the research aims to define factors that influence the negative perception of certain holiday destinations, the analysis included similar points of interest of tourists while choosing a destination, as well as the relevant factors that formed a negative perception towards other destinations.

According to first empirical research for year 2009 for Croatia, Montenegro and Bulgaria destination, results show tourists evaluation of negative parameters as reasons why they didn’t choose these destination for holiday in the year 2009 (Najdić, 2OII):

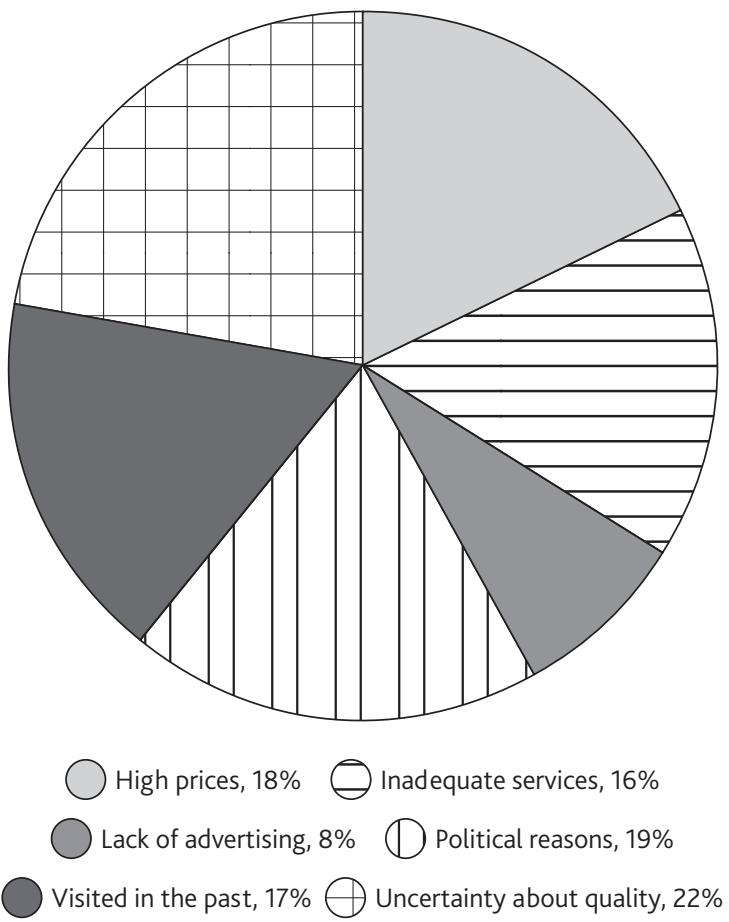

Figure 2. Evaluation of parameters for destinations in 2009

Further, summing all negative factors that influenced on the decision process (Figure 2), primary for tourists is the perceived quality of destination offer (attractiveness) with (22\%). Second is the influence of political factors (I9\%), the third is the price (I8\%), past experience (I7\%) and inadequate services (I6\%). The advertising has a negligible impact on tourists (8\%).

However, when the entire population is analyzed it can be concluded that the picture is somewhat different, the price is overwhelmingly the main factor. Totally $4 \mathrm{I} .6 \%$ of the tourists have indicated this as the decisive factor, followed by quality, $\mathrm{I} 6.4 \%$ and attractiveness of the destination and entertainment, $8.5 \%$ of the tourists respectively.

Having in mind that perception is formed on the basis of the information from the media, recommendations from friends or relatives, or to a lesser extent, tourists own experience, we 


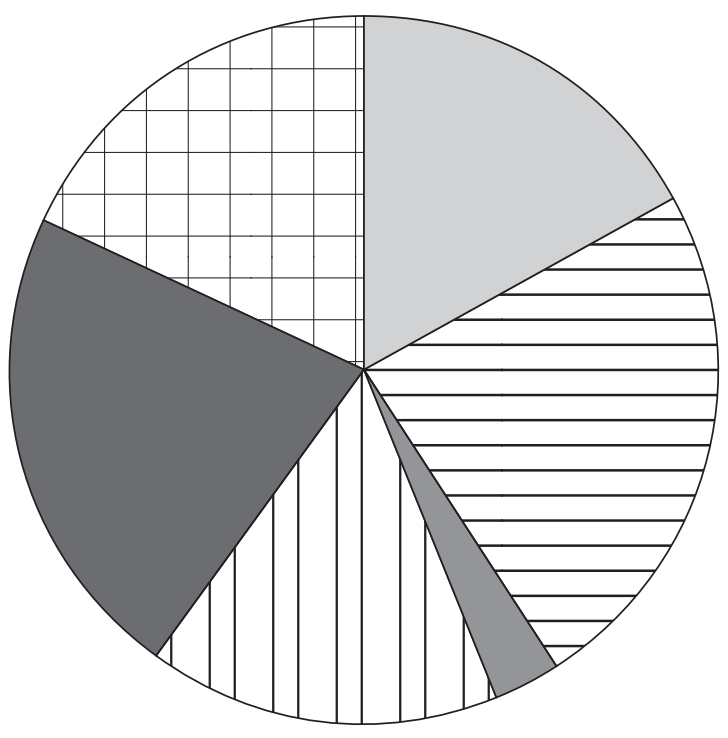

High prices, 17\% Inadequate services, 24\%

Lack of advertising, 3\% Political reasons, 16\%

Visited in the past, $22 \% \bigoplus$ Uncertainty about quality, $18 \%$

Figure 3. Reasons for not visiting Montenegro in 2006

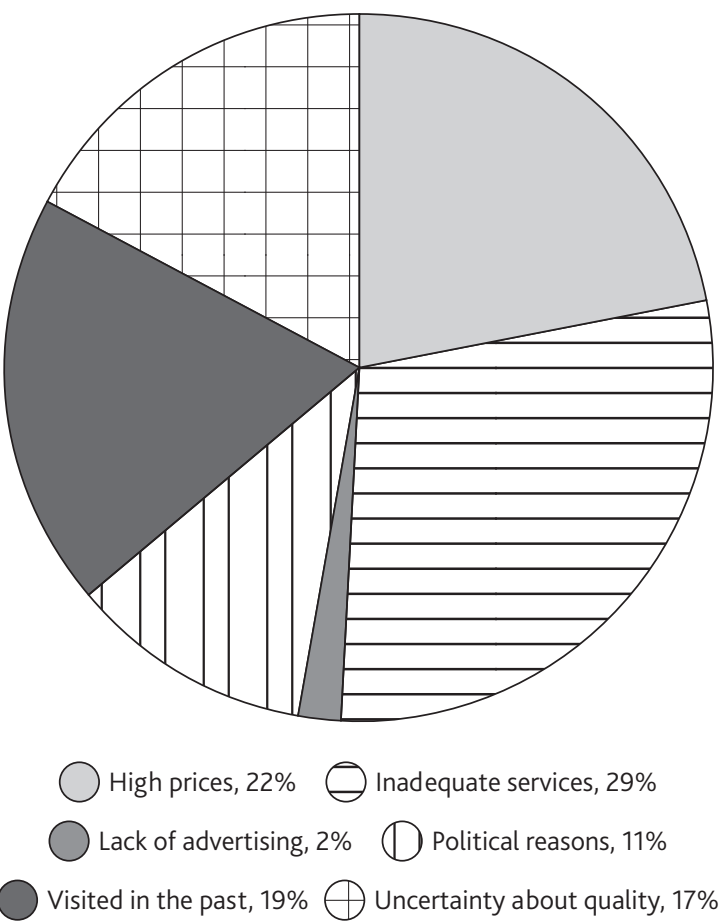

Figure 4. Reasons for not visiting Montenegro in 2009

come to the conclusion that, perceived attractiveness and economy factors have a decisive influence on tourists behavior and on choice of a holiday destination.

A number of scientists who analyze the destination brand are interested to find out why the brand has emotional influence on the tourists and what characteristics are important for their acceptability. Perception tests are different from scaling the quality, by using direct comparison of the cases (destinations) to define what each destination reflects on by specific feature. Since the perception is a complex, in the survey elements are distinguished and evaluated separately by respondents.

On example of Montenegro, we see that the majority of tourists (30\%) allocated inadequate service as a crucial reason for not choosing this destination for holiday (Figure 3 and Figure 4). As a second stated factor is the belief that prices do not match the quality of destination offer. Comparing research results for these two years, we see that three main factors that influenced the decision process of the tourists remained the same (inadequate services, high prices and visited in the past), but that the role of prices was more important this year than in year 2006.

However, the results of the research from 2OII and the official statistical data, shows that Montenegro remains a leading tourist destination when the entire population of Serbia is considered, $30 \%$, followed by Greece $26 \%$, and Serbia with I6\% of preferences. Montenegro is attractive also because of the fact that a passport is not required for the tourists of Serbia, thus affecting primarily the lower income population, who travels at most once per year for holidays. According to Monstat, Montenegro had a continuous growth of international arrivals. The peak of arrivals from Serbia was registered in $2008(4 \mathrm{I} 2, \mathrm{OOOO})$ followed by a sharp decrease in 2009 and $20 \mathrm{IO}$ (respectively 338,OOO and 3I4,OOO), a decrease of $25 \%$ in 
Table 7. Arrivals and overnight stays in Montenegro 2006-2010

\begin{tabular}{|c|c|c|c|c|}
\hline & \multicolumn{3}{|c|}{ International Arrivals, in 000} & \multirow{2}{*}{ Domestic arrivals, 000} \\
\hline & Total & From Serbia & Other Countries & \\
\hline 2006 & 797 & 378 & 419 & 156,8 \\
\hline 2007 & 984 & 389 & 595 & 149,2 \\
\hline 2008 & 1.031 & 412 & 612 & 156,9 \\
\hline 2009 & 1.044 & 338 & 706 & 163,6 \\
\hline 2010 & 1.087 & 314 & 773 & 175,1 \\
\hline
\end{tabular}

Source: Monstat, Statistical office of Jugoslavia and calculations of Sekulovic, Nin PhD Thesis in preparation

two years. It is clear that economic crises has caused the general decrease of leisure travels of the tourists of Serbia and primarily affected domestic destinations and Montenegro. The decrease of domestic arrivals in Serbia was from I,620,000 mln in 2008 to I,373,000 in 2009 and I,3I7,OOO in 2OIO, followed by overnight stays from 5,935,000 mln in 2008, to $5,293,000$ in 2009 and 4,96I,OOO in 2OIO, a decrease of 20\% in two years ${ }^{6}$.

From this table it can be concluded that Montenegro experienced a significant growth of international arrivals in the period 2OOI-2OIO, except from Serbia, followed by a modest growth of domestic arrivals.

On example of the Croatian holiday destination, we can see that in both observed years, political climate have a crucial impact on tourists from Serbia (Figure 5 and Figure 6). At the same time there is a significant difference in perceiving the quality of destination offer,
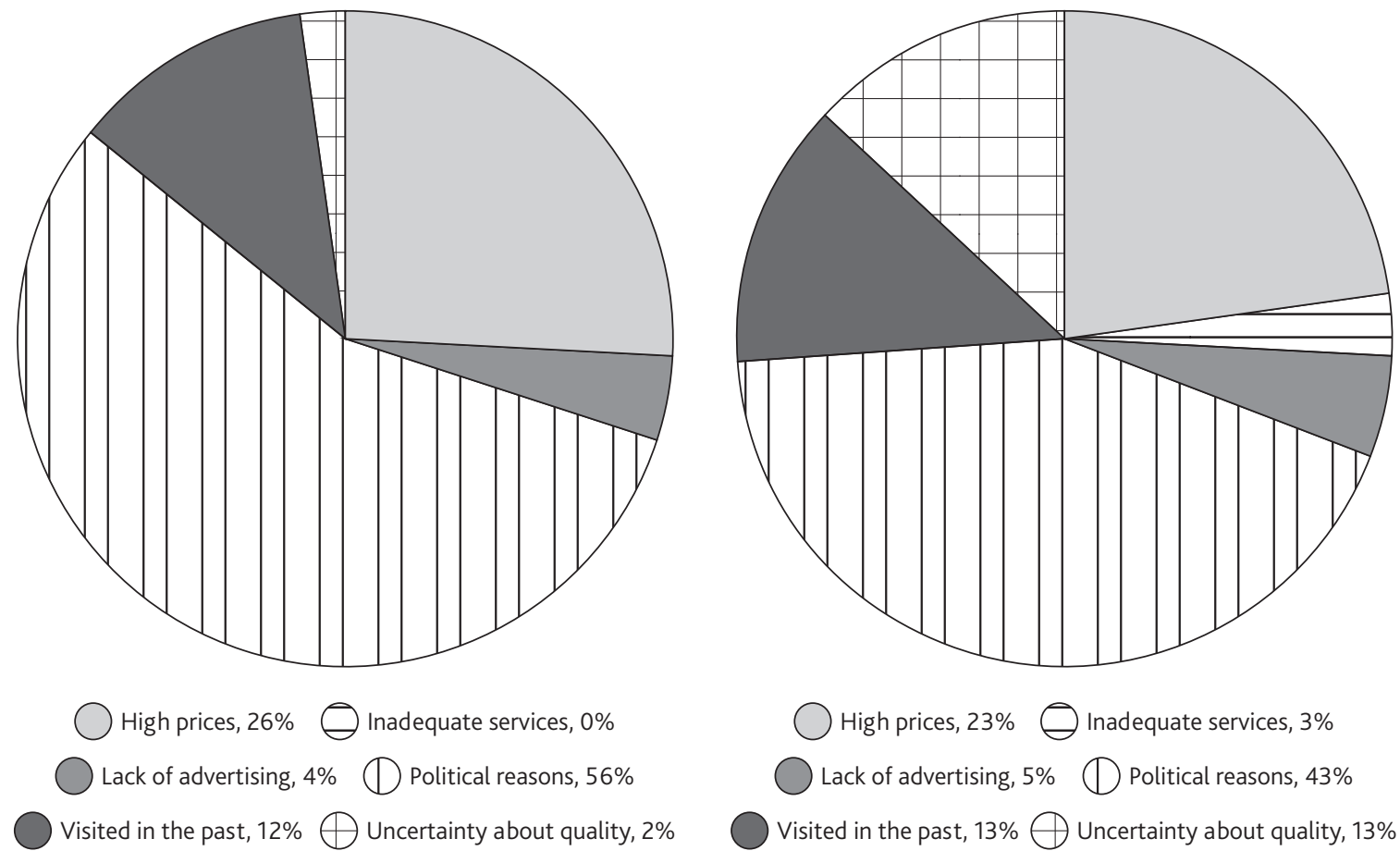

Figure 5. Reasons for not visiting Croatia in 2006

Figure 6. Reasons for not visiting Croatia in 2009

${ }^{6}$ Statistical Office of the Republic of Serbia, 2OII. 


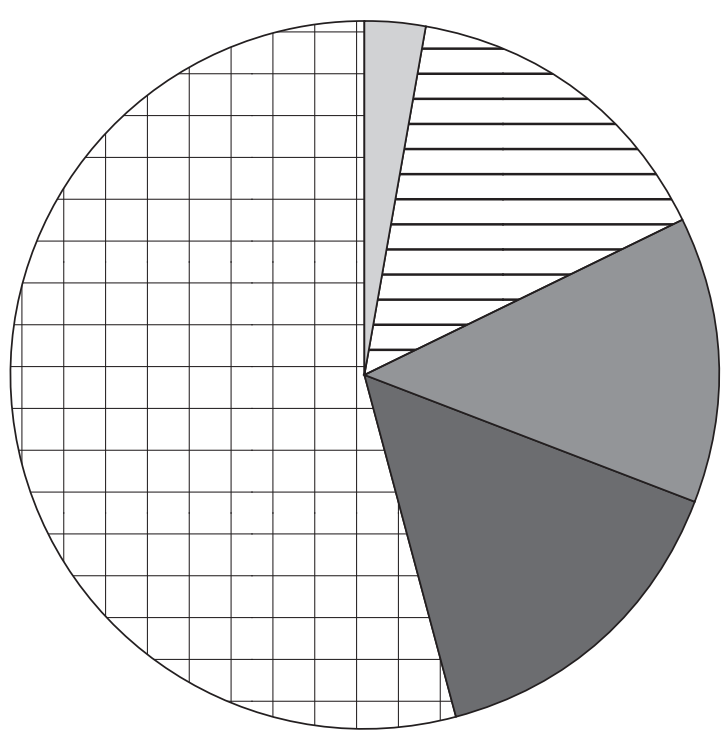

High prices, 3\% $\bigcirc$ Inadequate services, 15\% Lack of advertising, $13 \%$ Political reasons, $0 \%$

Visited in the past, $15 \% \bigoplus$ Uncertainty about quality, $54 \%$

Figure 7. Reasons for not visiting Bulgaria in 2006

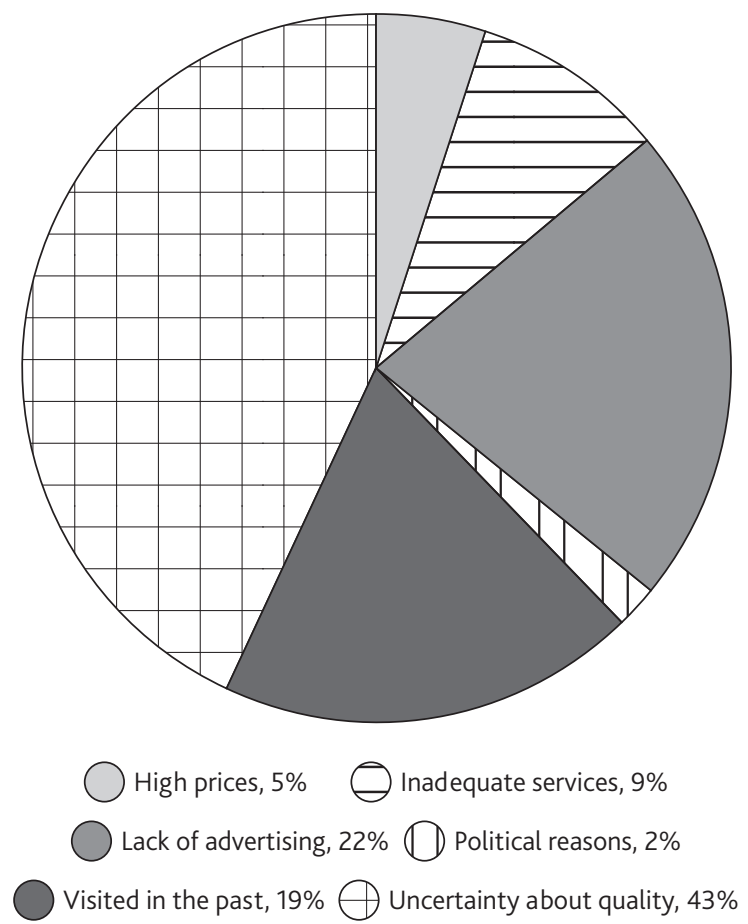

Figure 8. Reasons for not visiting Bulgaria in 2009

which is II\% higher compared to year 2006. What has also changed slightly is less influence of the political climate this year (decreased by I3\%), as is the case of Montenegro (less impact by $5 \%$ ). When tourists experienced a hostile atmosphere of the local population, in the same way they experienced (perceived) the destination. First authors who noticed the importance of these two factors are (Ritchie, Zins, 1978) who presented research on the influence of social behavior of the local population on the attractiveness of holiday destinations. According to the research on the entire population, Croatia as destination was chosen by $5.3 \%$ of the tourists, which represents a signal of an unutilized reservoir of tourists, even though probably very sensitive to political factors, more than to economic.

Observing Bulgaria as a holiday destination, the perception of quality is a crucial factor in process decision for choosing the destination (Figure 7 and Figure 8). Here is the also case, as with previous destinations, that tourists from Serbia have the same preferences towards these destinations.

In our research, experience of welcoming atmosphere is noticeable through the almost negligible effect of political factors on the perception that our tourists have of Bulgaria as a holiday destination. Important factor in 2009 was lack of advertising and the possible lack of information, which could eliminate the negative perceptions regarding the uncertainty in the quality of a destination offer. 


\section{Conclusions and Recommendations}

The Global economic crises has impacted negatively on the leisure travels of the population of Serbia. The majority of the tourists travel on average once per year, individually with their own transportation. Thus the economic crisis has affected the choice of destination but has not affected the choice of the transportation. The global economic crisis has had more influence on the general population and on a lesser scale on tourists who travel with travel agencies.

The price is the overwhelmingly predominant factor that influences the destination choice process of the general population, followed by service quality. While the main factor that influences those tourists travelling with travel agencies is attractiveness of the destination and the price becomes decisive after selecting a destination on the basis of the overall perception. However, Montenegro and domestic destinations had a significant decrease in Serbian tourists arrivals due to deteriorating economic conditions of Serbian population.

Political factors have more influence on the tourists traveling with travel agencies than on the general tourist population, and the first category is more relying on the informations received through mass media than the second one where recommendations and past experience are the most influential sources of information.

In order to predict future tourism trends, each destination needs to know what kind of expectations and preferences tourists have regarding to their leisure holidays. Therefore with a better understanding of factors that influence on their choice of a holiday destination, destinations can point out, throughout a brand activity, its advantages in the eyes of current and potential tourists. Destination brand is the one who will initially, in addition to the recommendations, attract tourism demand and therefore needs to have a special stability that will ensure its position at the list of most desirable holiday destinations, despite on the economy situation in the region.

\section{References}

Aaker, D., Kumar V., Day G., (2008). Marketinško istraživanje, deveto izdanje, CID Ekonomski fakultet, Beograd.

Bakić, O. (2005). Marketing u turizmu, Čigoja štampa, Beograd.

Cronin, J., Taylor, S. (1992). Measuring Service Quality: A Reexamination and Extension, Journal of Marketing, 56, 55-68.

Glaesser, D. (2004). Crisis Management in the Tourism Industry, Elsevier, Oxford, UK

Henderson, J. (2007). Tourism Crisis: Causes, Consequences and Management, Elsevier, Oxford, UK.

Johnson, P., Thomas, B. (eds), (I992). Choice and Demand in Tourism, Mansell Publishing, London.

Kozak, M., Rimmington, M., (I999). Measuring tourist destination competitiveness: conceptual consideration and empirical findings, International Journal of Hospitality Management, I8 (3), 273-283.

Mayo, E., Jarvis, L. (198I). The Psychology of Leisure Travel, CBI Publishing, Boston, Massachusetts.

Miljević, M. (2006). Poslovna etika i komuniciranje, Univerzitet Singidunum, Beograd.

MONSTAT, Statistički godišnjak. 
Najdić, M. (2OII). Using Multiple Senses in Service Experience Creating Consumer Loyalty in Tourism, International Journal of Management Cases, Access Press UK, I3 (3), I8-23.

Parasuraman, A., Zeithaml V.A. and Berry L.L. (1994): Reassessment of expectations as acomparison standard on measuring service quality: implications for further research, Journal of Marketing, 58 (I), III-I24.

Popesku, J. (2008). Menadžment turističke destinacije, Univerzitet Singidunum, Beograd.

Porter, M. (1980). Competitive Strategy: Techniques for Analyzing Industries and Competitors, The Free Press, New York.

Ritchie, B., Zins, M. (1978). Culture as a determinant of the Attractiveness of a Tourism.

Ross, G.F. (1998). The Psychology of Tourism, Second Edn, Hospitality Press Region, Annals of Tourism Research, 5 .

Sekulović, N. (2OII). The Impact of the Global Economic Crisis on the Attitudes of the Citizens of Serbia towards Leisure Travel, Singidunum Review, 8 (2), III-II8.

Statistički zavod Republike Srbije

Unković, S., Sekulović, N. (2OIO). Measures to Mitigate the Impact of Global Economic Crisis on Tourism, Singidunum Review, 7 (2), I8I-I92.

Unković, S., Zečević, B. (2OII). Ekonomika turizma, Ekonomski fakultet, Beograd.

Uysal, M., (ed.), (1994). Global tourist behavior, International Business Press, Binghamton, New York. 